\title{
Temporal change of ElA asymmetry revealed by a beacon receiver network in Southeast Asia
}

\author{
Kornyanat Watthanasangmechai ${ }^{1 *}$, Mamoru Yamamoto ${ }^{1}$, Akinori Saito ${ }^{2}$, Takashi Maruyama ${ }^{3}$, Tatsuhiro Yokoyama ${ }^{3}$, \\ Michi Nishioka ${ }^{3}$ and Mamoru Ishii ${ }^{3}$
}

\begin{abstract}
To reveal the temporal change of the equatorial ionization anomaly (EIA) asymmetry, a multipoint satellite-ground beacon experiment was conducted along the meridional plane of the Thailand-Indonesia sector. The observation includes one station near the magnetic equator and four stations at off-equator latitudes. This is the first EIA asymmetry study with high spatial resolution using GNU Radio Beacon Receiver (GRBR) observations in Southeast Asia. GRBR-total electron contents (TECs) from 97 polar-orbit satellite passes in March 2012 were analyzed in this study. Successive passes captured rapid evolution of ElA asymmetry, especially during geomagnetic disturbances. The penetrating electric fields that occur during geomagnetic disturbed days are not the cause of the asymmetry. Instead, high background TEC associated with an intense electric field empowers the neutral wind to produce severe asymmetry of the EIA. Such rapid evolution of EIA asymmetry was not seen during nighttime, when meridional wind mainly controlled the asymmetric structures. Additional data are necessary to identify the source of the variations, i.e., atmospheric waves. Precisely capturing the locations of the crests and the evolution of the asymmetry enhances understanding of the temporal change of EIA asymmetry at the local scale and leads to a future local modeling for TEC prediction in Southeast Asia.
\end{abstract}

Keywords: ElA asymmetry; GRBR; Beacon receiver network; Southeast Asia; Equatorial ionosphere; Thermospheric meridional wind; Geomagnetic disturbances

\section{Background}

The equatorial ionization anomaly (EIA) is a significant combined ionospheric feature. During the daytime, the $\mathrm{E} \times \mathrm{B}$ plasma drift around the geomagnetic equator is upward due to the eastward electric field, whereas it reverses at night. The plasma is lifted upward during daytime and then it diffuses away from the magnetic equator along geomagnetic field lines due to the Earth's gravitational and pressure gradient forces. The combination of electrodynamic drift (Martyn 1955) and diffusion (Mitra 1946) produces a fountain-like motion of the plasma known as the equatorial fountain effect. Consequently, ionization peaks, commonly known as EIA, form in both hemispheres. Namba and Maeda (1939) first discovered EIA before World War II (Rishbeth 2000). It was the major outcome of a study of the

\footnotetext{
* Correspondence: kukkai@rish.kyoto-u.ac.jp

${ }^{1}$ Research Institute for Sustainable Humanosphere (RISH), Kyoto University, Kyoto, Japan

Full list of author information is available at the end of the article
}

midday F2-layer critical frequency (fo $F 2$ ) from stations at different latitudes (Bailey 1948; Nishida 2009).

Interactions between transequatorial neutral winds and the strength of the equatorial fountain effect play important roles in the asymmetric development of the EIA crests. Aydogdu (1988) studied the thermospheric wind effect on EIA asymmetry for equinox seasons in African and West Asian regions and found that the $\mathrm{Nm} F 2$ in the northern crest was greater than that in the southern crest during daytime. Maruyama (1996) proposed that it is possible to determine the direction of the meridional neutral wind by using the ionospheric height variations at the magnetic equator and at the magnetic conjugate points in the same magnetic meridian.

The first low-latitude ionospheric tomography network (LITN) covering $14.6^{\circ} \mathrm{N}$ to $31.3^{\circ} \mathrm{N}$ (or $3.3^{\circ} \mathrm{N}$ to $19.7^{\circ} \mathrm{N}$ geomagnetic latitude) along $120^{\circ} \mathrm{E}$ longitude was initiated in 1991 (Yeh et al. 1994). These researchers measured the total electron content (TEC) from satellite dual-band beacons and subsequently explored the unique science

\section{Springer}


associated with the low-latitude ionosphere, e.g., EIA morphology and dynamics. Yeh et al. (2001) employed more than 350 ionospheric tomography images acquired in 1994. They found that the equatorial dynamo electric field is the main cause of the crest motion, and the correlation between the integrated strength of the electrojet and the strength of the equatorial fountain effect was high. They also showed that day-to-day variability of the EIA was controlled dominantly by the electrodynamics. These findings were deduced from observation in a low-solaractivity year from only the northern hemisphere. The LITN improved the study of the ionospheric structures at low latitudes on the Taiwan meridian.

Global-scale observations of ionospheric structures were conducted with six micro-satellites termed Formosa Satellite 3 and Constellation Observing System for Meteorology, Ionosphere, and Climate (FORMOSAT-3/ COSMIC or F3/C for short) (Cheng et al. 2006). Lin et al. (2007a) investigated EIA crests during July-August 2006 by employing the F3/C GPS occultation experiment. The EIA peak altitude and density from F3/C revealed clear longitudinal variability that is probably due to differences in magnetic declination, $\mathrm{E} \times \mathrm{B}$ drift, and the neutral winds at different longitudes. However, clear seasonal asymmetry was not seen in the TEC map (integrated from a 100 - to $500-\mathrm{km}$ altitude), except in the $50^{\circ}-150^{\circ} \mathrm{E}$ longitude regions. Although it provided valuable ionospheric information at the global scale, including over the oceans, the $\mathrm{F} 3 / \mathrm{C}$ could not provide high spatial resolution of the ionosphere at the same longitude.

Xiong et al. (2013) studied EIA morphology, interhemisphere asymmetry, and solar activity levels based on 9 years of CHAMP and GRACE observations. From their observations, crests were shown, based on global averages, to always be farther from the dip equator in the summer hemisphere at both CHAMP and GRACE altitudes ( $\sim 400$ and $\sim 480 \mathrm{~km}$, respectively). The electron density and magnetic latitudes of EIA crests were almost symmetric about the dip equator during the equinox season. The study using CHAMP and GRACE satellites globally revealed EIA information from a different altitude. However, it took 130 days for CHAMP (Reigber et al. 2002) and 160.5 days for GRACE (Tapley et al. 2004) to cover all local times in the same longitudinal sector.

Pancheva and Lysenko (1988) first reported a signature of the quasi-2-day oscillation in the peak electron concentration of the F-region ( $\mathrm{fo} F 2$ ). The wave period is in the range of 34 to $68 \mathrm{~h}$ (Pancheva et al. 2004). Chen (1992) found that there was a 2-day oscillation in the EIA. Forbes et al. (1997) suggested a possible connection between the 2-day oscillation in fo $F 2$ and the 2-day wave in the mesosphere and lower-thermosphere (MLT) region. Pancheva et al. (2006) observed a 2-day variability in geomagnetic fields due to E-region dynamo currents as well as modulation of tidal fields at E-region height. They suggested that the 2-day wave in the MLT region and the tidal field modulation could be attributed to the observed 2-day variation in the ionosphere. Takahashi et al. (2012) suggested that the 2-day-wave-induced thermospheric transequatorial wind could generate latitudinal transport of F-region plasma and therefore could cause day-to-day variability of EIA.

Although a number of studies have been carried out on EIA during the past seven decades, these studies have some limitations. For example, even though it provided ionospheric information with high spatial resolution, the LITN observation was limited to over only the northern hemisphere. Moreover, satellite observations are capable of capturing a global-scale distribution, but they are not good at capturing detailed structures. In addition, the F3/C did not allow consecutive observation at the same longitude, and the observations from the CHAMP and GRACE satellites took long collection times (130 and 160.5 days, respectively) to cover all local times at the same longitude. Finally, there has been no significant study of the precise structures of the EIA asymmetry across the geomagnetic equator, e.g. the locations of its crests (Chen et al. 2008). In this paper, we examine precise latitudinal structures of EIA over the Thailand-Indonesia region from a satellite-ground beacon experiment. The observation features are as follows: 1) EIA is observable in a narrow longitudinal coverage $(\sim 100 \mathrm{~km}) .2)$ The latitudinal extent at the ionospheric pierce point (IPP) covers \pm 25 geomagnetic latitude. 3) Each observation has a quick scan within $20 \mathrm{~min}$ on average. 4) The availability of the SouthEast Asia Low-latitude IOnospheric Network (SEALION) provides information regarding the ionosphere's condition and meridional wind behavior.

\section{Methods}

The GNU Radio Beacon Receiver (GRBR) was first designed and developed by Yamamoto (2008) to receive beacon signals in VHF and UHF bands from low earth orbit (LEO) satellites. A multipoint beacon experiment along $100^{\circ} \mathrm{E}$ began collecting observations in March 2012. The ionosonde chain under the SEALION project (Uemoto et al. 2007), which is a joint project among several countries including Japan, Thailand, and Indonesia, is also along this same meridian. Both GRBR and the ionosonde networks now cover the geomagnetic northern and southern hemispheres, including the geomagnetic equator, in Southeast Asia. The locations of these networks are summarized in Table 1. Data from the GRBRs and ionosondes from March 2012 are mainly used in this paper. 
Table 1 GRBR and ionosonde network information

\begin{tabular}{|c|c|c|c|c|c|}
\hline \multirow[t]{2}{*}{ Site } & \multicolumn{2}{|c|}{ Geographic } & \multirow{2}{*}{$\begin{array}{l}\text { Dip } \\
\text { latitude }\end{array}$} & \multirow[t]{2}{*}{ Country } & \multirow{2}{*}{$\begin{array}{l}\text { Available } \\
\text { observation }\end{array}$} \\
\hline & Latitude & Longitude & & & \\
\hline Chiang Mai & 18.76 & 98.93 & 12.7 & Thailand & $\begin{array}{l}\text { GRBR and } \\
\text { ionosonde }\end{array}$ \\
\hline Bangkok & 13.73 & 100.78 & 6.7 & Thailand & GRBR \\
\hline Chumphon & 10.72 & 99.37 & 3.0 & Thailand & $\begin{array}{l}\text { GRBR and } \\
\text { ionosonde }\end{array}$ \\
\hline Phuket & 8.09 & 98.39 & -0.2 & Thailand & GRBR \\
\hline Kototabang & -0.20 & 100.32 & -10.1 & Indonesia & $\begin{array}{l}\text { GRBR and } \\
\text { ionosonde }\end{array}$ \\
\hline
\end{tabular}

Generally, EIA is expected to be symmetric during the March equinox. To see whether or not the GRBR can reveal the precise EIA structure, we precisely investigated the asymmetry of EIA. In Southeast Asia, a plasma bubble influence is also active in March. Small asymmetry is seen during plasma bubble appearance. We thus selected the March equinox for this study to highlight the sensitivity of the GRBR (Yamamoto 2008) and the robustness of the TEC estimation technique (Watthanasangmechai et al. 2014).

To capture EIA asymmetry, the signals from polar LEO satellites, for which orbital heights are $1000 \mathrm{~km}$ on average, are used to estimate GRBR-TEC. In this work, GRBR-TEC is the vertical TEC between the satellite altitude and ground, and the GRBR-TECs from 97 passes of polar-orbit satellites during March 2012 are analyzed. The units of GRBR-TEC are TEC units, $10^{16} \mathrm{el} / \mathrm{m}^{2}$, and the satellite information is summarized in Table 2. The estimation technique of the absolute TEC from the latitudinal network of GRBR is explained in Watthanasangmechai et al. (2014). We assume that the EIA structure is stable over one satellite pass. Each satellite pass over the field of view of the five GRBRs covers about $20 \mathrm{~min}$ in time and $6000 \mathrm{~km}$ in distance at IPP altitude. IPP altitude is determined by the ionospheric height obtained from ionosondes. By connecting the TEC data from the meridional network of five GRBR sites, we can estimate the precise latitudinal TEC distribution around at most \pm 25 geomagnetic latitude. This quick scan allows the EIA

Table $\mathbf{2}$ Information about the polar LEO satellites used in this work

\begin{tabular}{lllll}
\hline Satellite name & $\begin{array}{l}\text { Inclination } \\
\text { (degrees) }\end{array}$ & Apogee $(\mathrm{km})$ & Perigee $(\mathrm{km})$ & Period $(\mathrm{min})$ \\
\hline COSMOS2407 & 83 & 1008 & 952 & 105 \\
COSMOS2414 & 83 & 967 & 910 & 103.8 \\
COSMOS2429 & 83 & 1011 & 953 & 105 \\
COSMOS2463 & 83 & 1021 & 969 & 105 \\
DMSPF15 & 98.9 & 851 & 837 & 101.8 \\
RADCAL & 89.5 & 900 & 791 & 101.4 \\
\hline
\end{tabular}

structures from both hemispheres to be captured clearly with high spatial resolution and without interpolation. Successive passes enable us to capture the temporal change of the EIA asymmetry.

The SEALION ionosonde is operated to continuously transmit radio waves from 2 to $30 \mathrm{MHz}$ and receive echoes from the ionosphere in order to provide a bottomside plasma density profile every 15 min (Kenpankho et al. 2011). The data from SEALION are used to estimate a proxy of the transequatorial wind by following the method proposed by Maruyama et al. (2008).

\section{Results and discussion}

\section{EIA formation and daily variation}

Figure 1 shows the daily variation of the 2-h binned GRBR-TEC of EIA for the whole period beginning from the 06-07 LT bin (top left panel) and ending at the 0405 LT bin (bottom right panel). The $K_{\mathrm{p}}$ index for March 2012 is shown in Fig. 2. The data represented in Fig. 1 are during $K_{\mathrm{p}}<3-$. The yellow line represents the latitudinal TEC profile. The numbers of latitudinal profiles used in each panel are as follows: two profiles for the 06-07 LT bin, one profile for the 08-09 LT bin, one profile for the 10-11 LT bin, two profiles for the 12-13 LT bin, five profiles for the 14-15 LT bin, eight profiles for the 16-17 LT bin, four profiles for the 18-19 LT bin, ten profiles for the 20-21 LT bin, five profiles for the 22-23 LT bin, four profiles for the 00-01 LT bin, five profiles for the $02-03 \mathrm{LT}$ bin, and two profiles for the 04-05 LT bin. The horizontal axis on each plot presents geographic latitude. The geomagnetic equator for $100^{\circ} \mathrm{E}$ is located at $7.8^{\circ} \mathrm{N}$ geographic latitude. The inclination of the geomagnetic field is close to zero. The black error bars represent the standard deviation $(\sigma)$ of the TEC at every degree. In the morning (06-07 LT), the plasma density is extremely low when the plasma is that surviving through the night. TEC is dominant from the subsolar latitude $\left(0^{\circ}\right.$ geographic latitude $)$ to the south at post-sunrise (06-07 LT). TEC increases rapidly from 06 to $09 \mathrm{LT}$, which is an ordinal behavior after sunrise. TEC is dominant and has an arch shape around the dip equator. EIA crests are seen within the 10-11 LT bin, suggesting that EIA starts forming during this time. Whereas the northern crest is clearly dominant at the 10-11 LT and 12-13 LT bins, the southern crest becomes dominant after the 16-17 LT bin. The TECs at both hemispheres are quite symmetric during the 14-15 LT bin. The TECs at both hemispheres reach their peaks, as high as 70 TEC units (TECU) on average, during the 14-17 LT bin. The EIA then decays gradually from the 18-19 LT bin. The $\sigma$ at the dip equator is larger at 18-19 and 20-21 LT compared with daytime. The EIA crests decay rapidly at 22-23 LT. The crest-to-crest width becomes smallest before the crests disappear at 00-01 LT. 


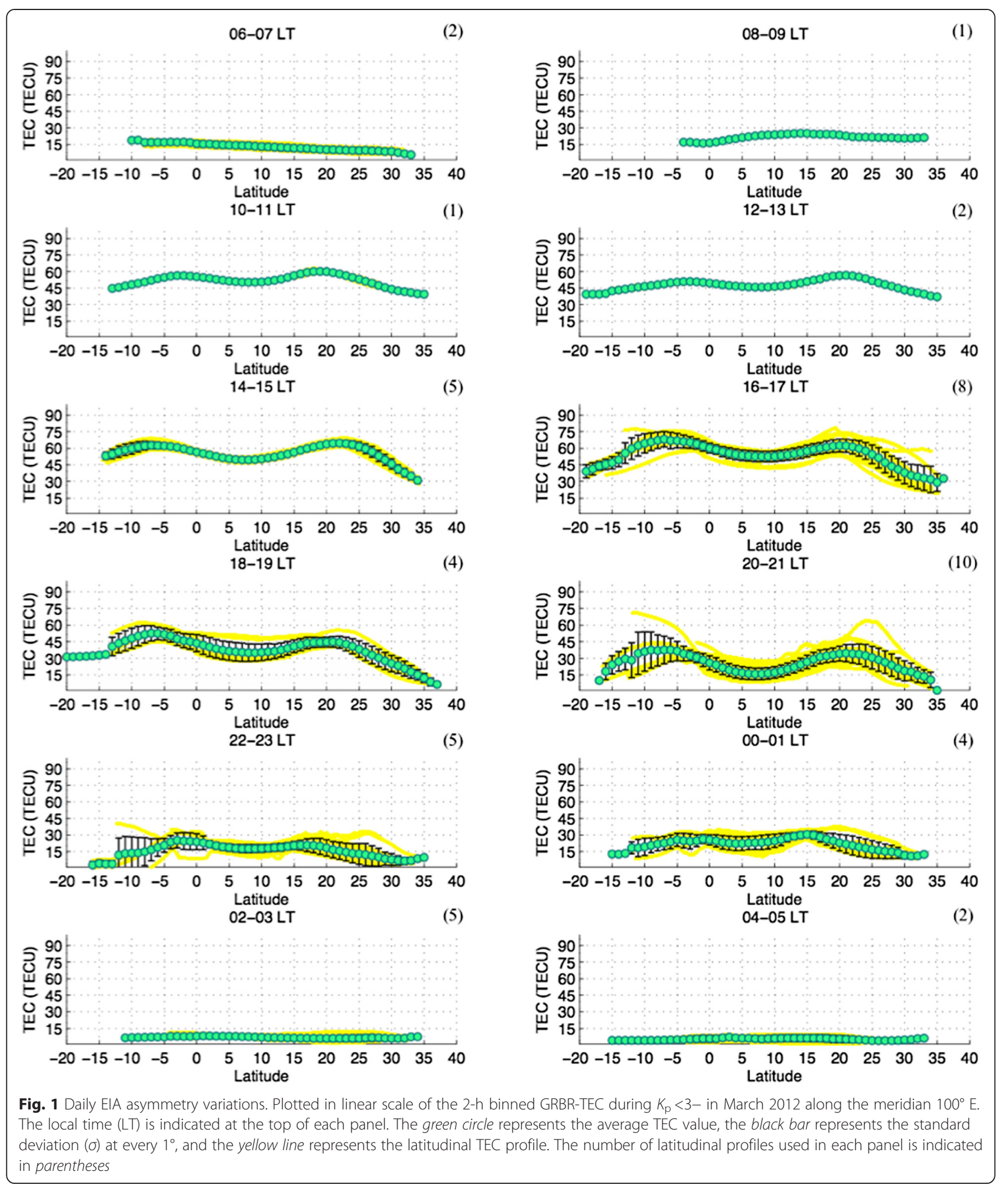

After midnight (02-05 LT), the TEC in both hemispheres and at the dip equator decreases further until it reaches the daily minimum just before sunrise (04-05 LT).

Figure 3 shows the EIA asymmetry parameters during $K_{\mathrm{p}}<3$ - in March 2012 with 2-h resolution. The TECs at the EIA crests and center are plotted in Fig. 3a. The TEC ratio, which is the ratio of the TEC of the northern crest to the TEC of the southern crest, is shown in Fig. 3b. The TEC ratio is larger than 1 when the TEC value of the northern crest is higher than that of the 


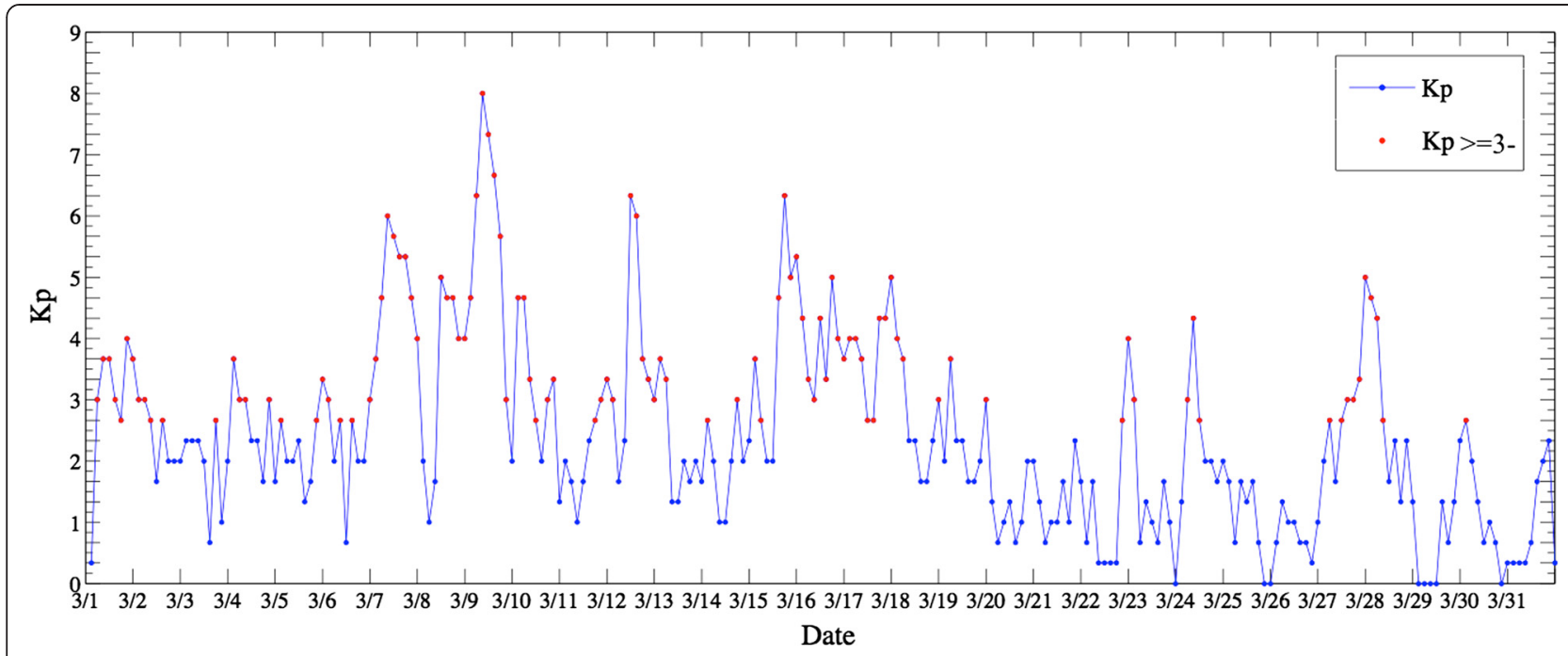

Fig. $2 K_{p}$ index in March 2012. Plotted every $3 \mathrm{~h}$ with blue line. The red " $\mathrm{O}$ " mark indicates the $K_{\mathrm{p}}<3-$

southern crest. The locations of the EIA crests and center are plotted in Fig. 3c. The crest peak latitude ratio, which is the ratio of the latitudinal width between the crest and the center in the northern hemisphere and that in the southern hemisphere, is shown in Fig. 3d. The crest peak latitude ratio is smaller than 1 when the crest peak latitude value in the northern hemisphere is smaller than that in the southern hemisphere. The latitudinal crest-to-crest width in degrees is illustrated in Fig. 3e. Figure $3 f$ shows the expansion speed of the crests in degrees per hour. A positive speed means that the crests are expanding in the poleward direction, whereas a negative speed indicates equatorward motion of the crests. The TECs around the dip equator appear stable at about 50 TECU during 1030-1630 LT. This is probably due to a balance between ion production and the up-drift effect at the dip equator. As the fountain effect occurs repeatedly, the EIA crests at the off-equator continue developing until afternoon. The EIA crest-tocrest latitudinal width, which depends on the zonal electric field strength, continues to expand from $1030 \mathrm{LT}$ to 1430 LT, as shown in Fig. 3e. The TEC is dominant in the northern hemisphere during 1000-1430 LT, when EIA expands rapidly.

The transition of the daytime north-south asymmetry is at $15 \mathrm{LT}$, as shown in Fig. 3b. Before the transition hour, the expansion speed of the EIA decreases from $2^{\circ}$ to $0^{\circ} / \mathrm{h}$. The expansion speed is quite constant at around $0^{\circ} / \mathrm{h}$ after $15 \mathrm{LT}$. The average apex height of the EIA crests reaches $860 \mathrm{~km}$. The TEC at the dip equator reaches its peak at $52.42 \mathrm{TECU}$ at $1630 \mathrm{LT}$.

Near the dusk terminator, the equatorial $F$-layer rises due to the action of the dynamo electric fields; subsequently, it descends, and this descent is known as pre-reversal enhancement (PRE). The expansion speed increases suddenly around 1930 LT, probably due to the PRE. The crest-tocrest latitudinal width reaches its peak of $30^{\circ}$ when the expansion speed increases from $0^{\circ}$ to $1^{\circ} / \mathrm{h}$. After 1930 LT, the expansion speed turns negative, which indicates a decrease of the EIA crest-to-crest width. The crestto-crest latitude decreases rapidly from $30^{\circ}$ in the 20 $21 \mathrm{LT}$ bin to $20^{\circ}$ in the 22-23 LT bin with an expansion speed of $-5^{\circ} / \mathrm{h}$. The TEC continues to decrease after sunset, while the southern hemisphere continues to dominate until pre-midnight. The TEC at the dip equator increases slightly at pre-midnight, probably due to the midnight temperature maximum (MTM) (Colerico et al. 2006; Maruyama et al. 2008).

As a result of daily variation, the EIA is centered in the range of $7^{\circ} \mathrm{N}-9^{\circ} \mathrm{N}$, except at $0030 \mathrm{LT}$ (24.5 LT in Fig. 3) when the center appears at $4^{\circ} \mathrm{N}$; the northern crest appears in the range of $15^{\circ} \mathrm{N}-21^{\circ} \mathrm{N}$; and the southern crest appears in the range of $1^{\circ} \mathrm{S}-9^{\circ} \mathrm{S}$. The average location of the EIA center is near the dip equator, and the average locations of northern crest and southern crest are $19.4^{\circ} \mathrm{N}$ and $6.5^{\circ} \mathrm{S}$, respectively. By ignoring the crest and center information at $0030 \mathrm{LT}$, the crest is $2^{\circ}$ farther from the dip equator in the southern hemisphere compared to the northern hemisphere. The asymmetry is also shown in Fig. 3d, as the average of the crest peak latitude ratio is 0.93 . The EIA crests are fairly asymmetric after 1230 LT in this period average. The maximum TEC at both hemispheres and at the dip equator appears in the afternoon hours (1630 LT).

\section{EIA day-to-day variability}

The day-to-day variability of EIA can be interpreted using the $\sigma$ in Fig. 1. Note that the $\sigma$ at both ends of each TEC variation might be affected by the satellite pass coverage; therefore, these will be disregarded in the 


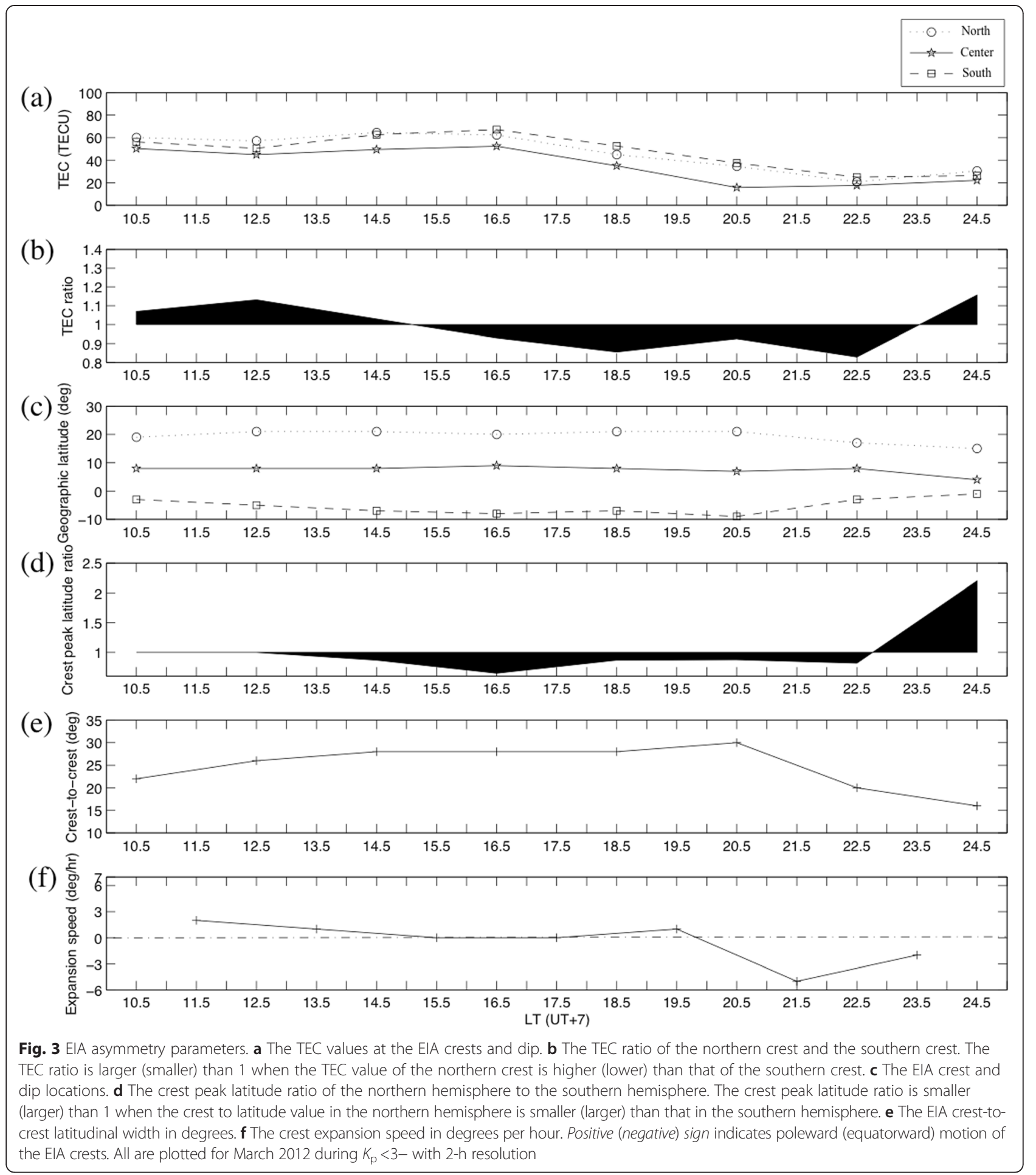

discussion. At post-sunrise (06-07 LT), the $\sigma$ is small and quite constant because the background plasma is low and the dynamo electric field cannot greatly affect the day-today variability. In the morning (08-09 LT), the EIA dayto-day variability is controlled mainly by the day-to-day variability of electric field strength responsible for the background current (Stolle et al. 2008). In the 10-11 LT bin, the $\sigma$ cannot be interpreted because only one overpass is available. In the 12-13 LT bin, the $\sigma$ is small, suggesting that day-to-day variability of the EIA is small during its developing phase. In the 14-15 LT bin, the $\sigma$ is still small at the dip equator, and it becomes slightly large around 
the EIA crests. This means that there is almost no dayto-day variability at the dip equator but that it exists around the crest latitudes. A large day-to-day variability around the crest latitudes is possibly contributed from the day-to-day variability of the crest locations and the EIA asymmetry during daytime. The $\sigma$ at the dip equator is extremely low during daytime (10-15 LT), probably due to the balance between the ion production from solar radiation and the upward $\mathrm{E} \times \mathrm{B}$ drift. At 16$17 \mathrm{LT}$, the $\sigma$ becomes large compared to the $\sigma$ in the previous hours in all latitudes. At night, the $\sigma$ is also large in all latitudes.

At night (18-01 LT), the EIA asymmetry is affected mainly by the temporal and day-to-day variability of the neutral wind (see below). In Southeast Asia, the March equinox is a favorable season for post-sunset plasma bubbles. In addition to the day-to-day variability itself, the plasma bubbles probably contribute to the large $\sigma$ at night. In particular, relative variability of the TEC at the EIA crests is enhanced during 20-23 LT, when an equatorial spread $\mathrm{F}$ (ESF) and/or plasma bubbles are expected to occur. Shallow ripples considered as a plasma bubble characteristic on latitudinal GRBR-TEC (Watthanasangmechai et al. 2014) can be seen in the background yellow lines during 20-01 LT. In addition to the ripples in the GRBR-TEC profiles, the large variability of crest location contributes to the large $\sigma$ at night. Note that the GRBR-TEC estimation error is about $3 \%$ at night, whereas it reaches $10 \%$ during ESF appearances (Watthanasangmechai et al. 2014).

Nighttime plasma bubbles are expected to occur around midnight (00-01 LT). Nevertheless, the March equinox during a high solar activity year is not a suitable condition for the event, and we did not find such an event from continuous observations using the Equatorial Atmosphere Radar. However, as shown in Fig. 1, while the averaged TEC is as large as 20 TECU, the relative $\sigma$ becomes large for all latitudes. This enhanced relative $\sigma$ might be caused by the day-to-day variability of the location of the EIA crests and the TEC value at decay time, and it may suggest a potential unstable situation. After the period, the relative $\sigma$ decreases until predawn.

Figure 4 shows the TEC variations from March 5 to 9 (from top to bottom) from $11 \mathrm{LT}$ to $01 \mathrm{LT}$. The time variation is separated into five bins: the 11-13 LT bin (noon), the 14-16 LT bin (afternoon), the 17-19 LT bin (evening), the 20-22 LT bin (night), and the 23-01 LT bin (midnight). These time bins are arranged from left to right, respectively, in Fig. 4. The daytime sector starts from noon to afternoon (11-16 LT), and the nighttime sector starts from evening to midnight (17-01 LT). The blank indicates lack of data. Well-developed EIA crests and the deep valley at the dip equator, which indicate intense electric fields, can be seen on March 8 at noon and on March 7 and 8 in the afternoon. High TECs at the EIA crests that are more than 80 TECU can be seen on March 8 at noon and on March 7-9 in the afternoon. The $K_{\mathrm{p}}$ index, considered as a proxy of geomagnetic activity, is shown in Fig. 2. The geomagnetic field condition was no-storm $\left(K_{\mathrm{p}}<4\right)$ on March $5-6$, and there was a major storm $\left(5 \leq K_{\mathrm{p}} \leq 6\right)$ on March $7-8$ and a severe storm $\left(K_{\mathrm{p}}>6\right)$ on March 9. During the morning hours (01-09 LT) of March 9, the Dst indices decreased to less than $-100 \mathrm{nT}$, and the $\mathrm{AE}$ indices reached more than $1000 \mathrm{nT}$; this period is therefore classified as an intense geomagnetic storm. It is likely that the intensive EIA during the daytime on March 7-9 and the positive storm are correlated. These characteristics, however, were not noticeable in the nighttime sector. This suggests complex temporal variability of the background neutral wind. The TEC variations at night during March 7-9 were as normal as those on the other days.

During intense geomagnetic storms, the enhanced neutral wind and composition changes can penetrate all the way to the equatorial region. During the early stages of a magnetic storm, strong electric fields can penetrate to the low-latitude ionosphere (Gulyaeva et al. 2011) and create a region of strong plasma drift (Kelley 2009). Zonally eastward electric field penetration causes an uplift of the daytime equatorial ionosphere, removes ions from the recombination zone, and allows for further production of plasma in sunlight at higher altitudes. This uplift eventually leads to an enhanced fountain effect and an expansion of the EIA crests to higher latitudes. The electron density also increases as a result of storm dynamics (Cherniak et al. 2014). This is known as a positive ionospheric storm (Schunk and Nagy 2009; Simi et al. 2013).

Figure 5 shows the EIA asymmetry variation in March 2012 for quiet days $\left(K_{\mathrm{p}}<3-\right)$ and disturbed days $\left(K_{\mathrm{p}} \geq 3-\right)$. The 14-15 LT bin is used to represent the daytime variation, and the $22-23 \mathrm{LT}$ bin is used to represent the nighttime variation. The effect of the positive ionospheric storm (Liu et al. 2004; Klimenko et al. 2012) on the TEC variation during the daytime can be seen. As shown in Fig. 5a, c, the $\sigma$ and average TEC in the daytime during the disturbed days are large compared to those during the quiet days, and similar behaviors have been described in other reports (Kutiev et al. 2006; Lin et al. 2007b; Kumar et al. 2014). The high $\sigma$ around the EIA crests during the disturbed days could be caused by the highly variable penetration of the electric field that controls the strength of EIA. On the other hand, there is no significant difference in the $\sigma$ during the quiet days and on the disturbed days at night. This suggests that high/low $K_{\mathrm{p}}$ affects the behavior of daytime but not nighttime EIA.

As mentioned above, strong day-to-day variability around the EIA crests was most dominant from 20 to 23 


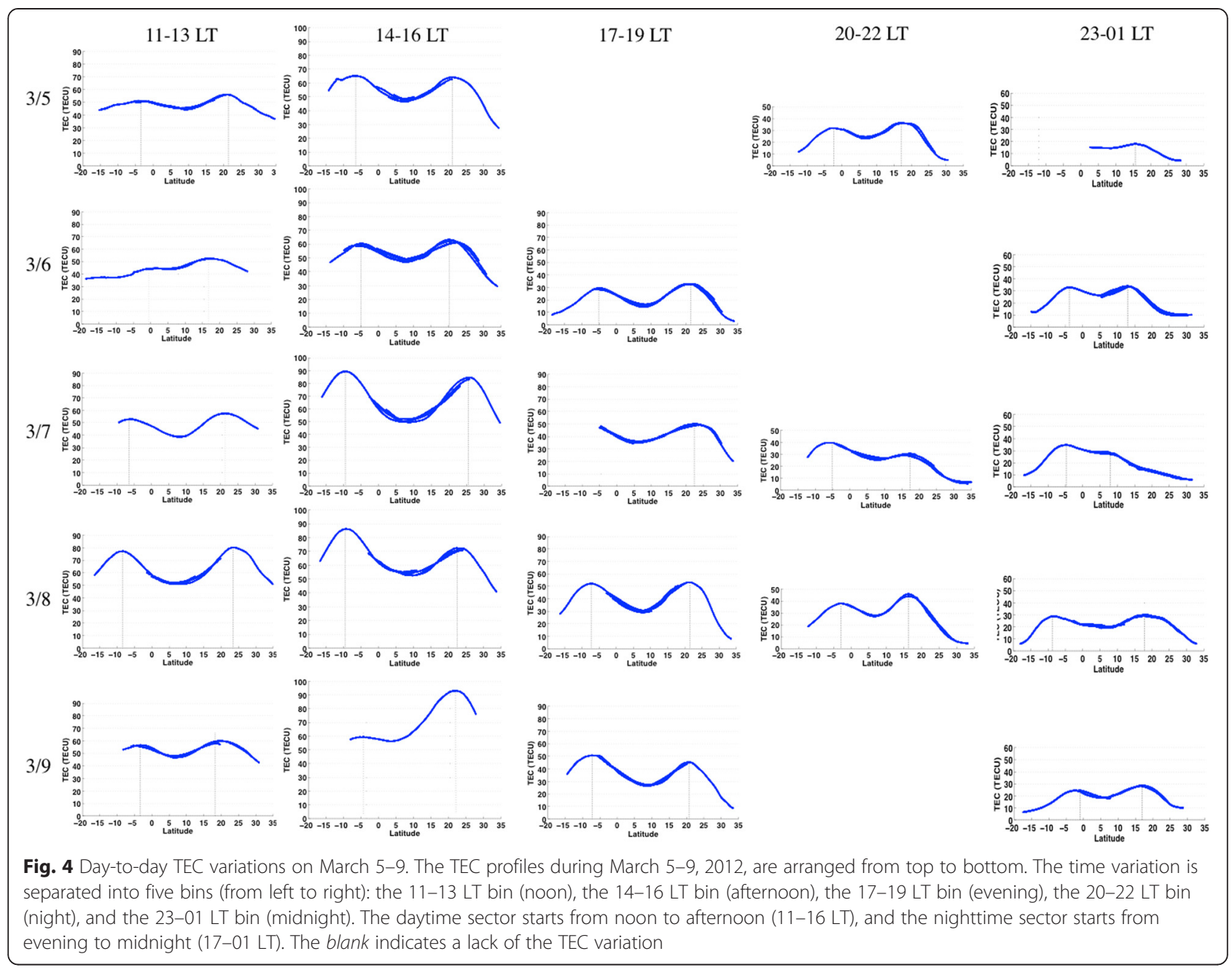

LT. We thus investigated TEC in the 20-23 LT bin for nighttime day-to-day variation. The nighttime TEC variation from March 3 to 9 is illustrated in Fig. 6. Figure 6d is picked from the previous bin, where the pass on March 6 at 19:52 LT is available to fill the data gap. North-south asymmetry is clearly shown. The TEC was larger in the northern hemisphere on March 3, larger in the southern hemisphere on March 4, and larger in the northern hemisphere on March 5. Additionally, the TEC was larger in the northern hemisphere on March 6, larger in the southern hemisphere on March 7, and larger in the northern hemisphere on March 8. The TEC variations on March 3-5 and on March 6-8 have the same trend. The TEC on March 9 was larger in the northern hemisphere as expected. There are no data on March 10. The TEC on March 11 was expected to be dominant in the northern hemisphere; however, as shown in Fig. 7a, the opposite occurred. The consecutive observations during March 3-9, 2012, however, cover both quiet and disturbed days. The neutral wind inducing the EIA asymmetry during a geomagnetic storm could also take part in producing the TEC variation. In this work, we discussed the effect of the meridional wind on the nighttime EIA asymmetry.

\section{EIA asymmetry}

The neutral wind is typically considered the primary source of EIA interhemispheric asymmetry, whereas the zonal electric field is secondary. The magnetic inclinations at the bottom $F$-layer altitude are $25.413^{\circ}$ and $-19.073^{\circ}$ at Chiang Mai and Kototabang, respectively. The thermospheric meridional wind is linked with the parallel upward motion along the geomagnetic field lines. The vertical component of the parallel upward velocity of plasma can be derived from the change of the $F$-layer bottom height. Because zonal electric fields also affect the upward drift of plasma, the effect from zonal electric fields is removed in order to use the $F$-layer bottom height for the transequatorial meridional wind estimation. The application to link meridional wind with an actual $F$-layer bottom height is limited to nighttime (Maruyama et al. 2008). 


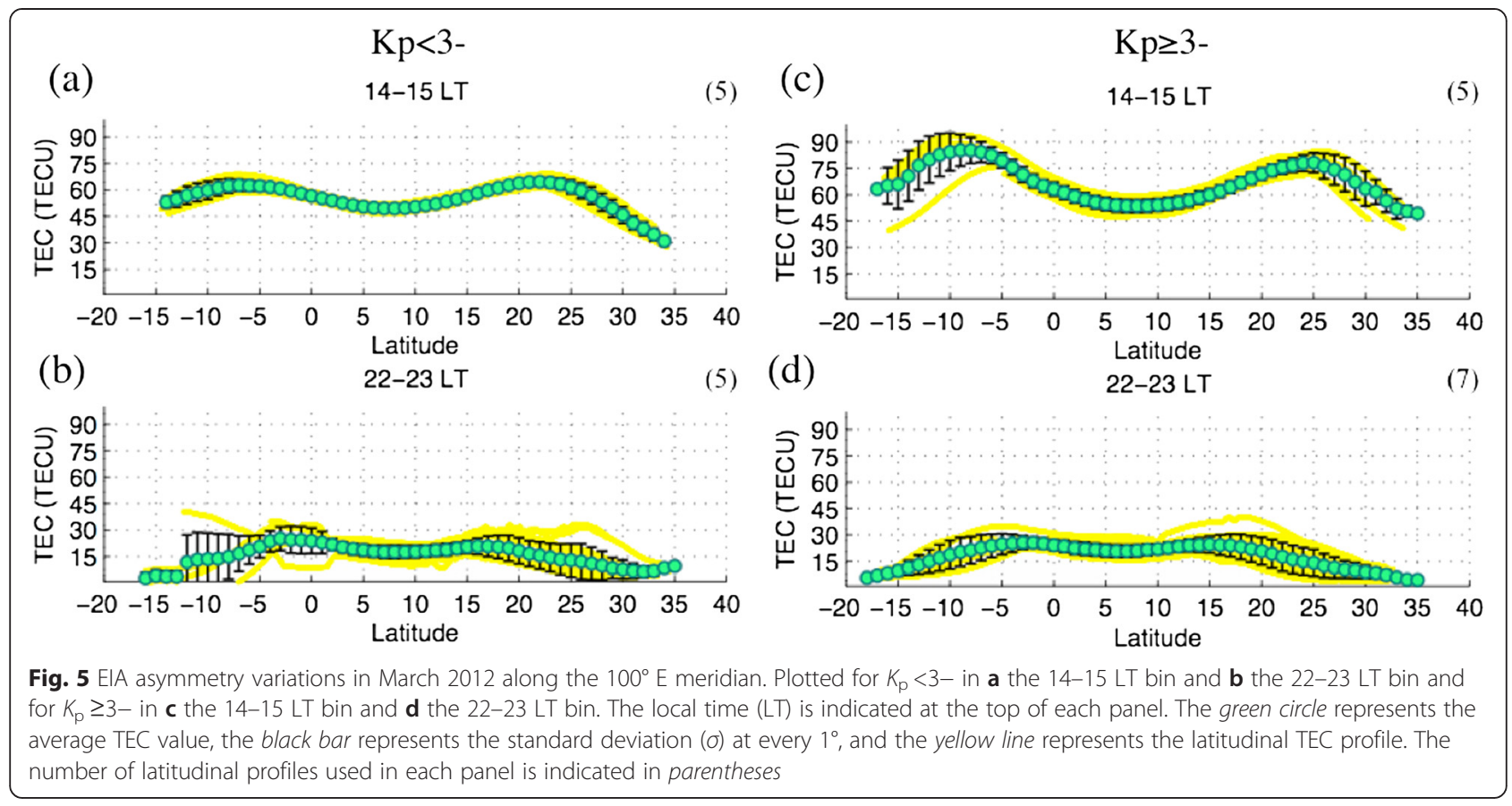

In this study, we estimate meridional neutral wind during nighttime in a magnetic meridional plane by taking the double difference of the ionospheric height change from a no-wind reference at conjugate points. The wind estimation method is explained in Maruyama et al. (2008). The double differential height is used as a proxy of the transequatorial meridional wind at about $250-\mathrm{km}$ altitude. Figure $7 \mathrm{a}, \mathrm{b}$ shows examples of the double differential heights as a proxy of the meridional wind on March 11 and March 26, 2012, which are the quiet days. The height change in kilometers is read as the wind velocity in meters per second, and the positive (negative) sign corresponds to the northward (southward) direction (Maruyama et al. 2009).

The response to the northward (southward) wind is expected because the northward (southward) wind induces decreasing TEC in the northern (southern) hemisphere. This is because the northward (southward) wind drags the plasma away from the southern (northern) hemisphere along the trough across the dip equator to the other hemisphere. The plasma is then forced to lower altitude by the neutral wind and by the Earth's gravitational force. Since there is no solar input to generate photoionization at night, the plasma that reaches

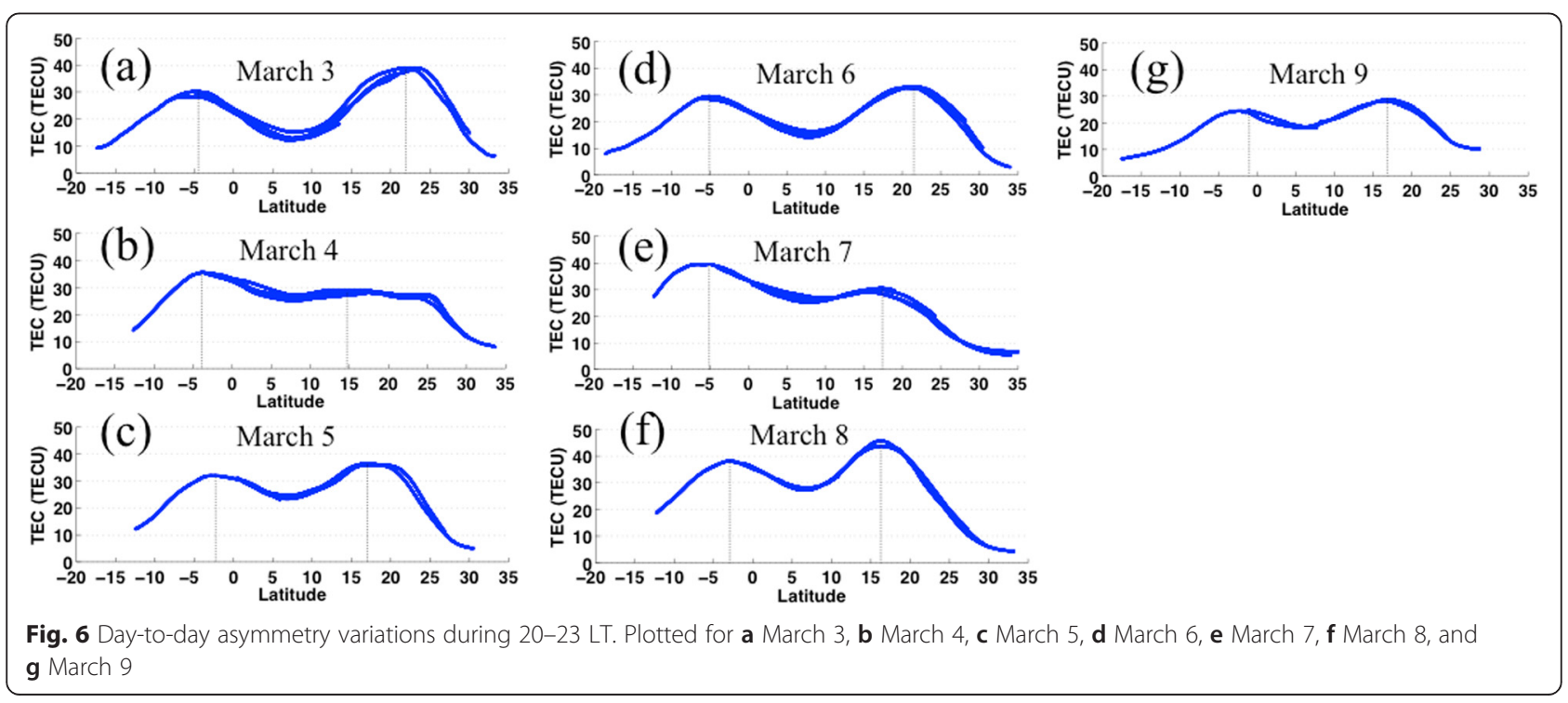




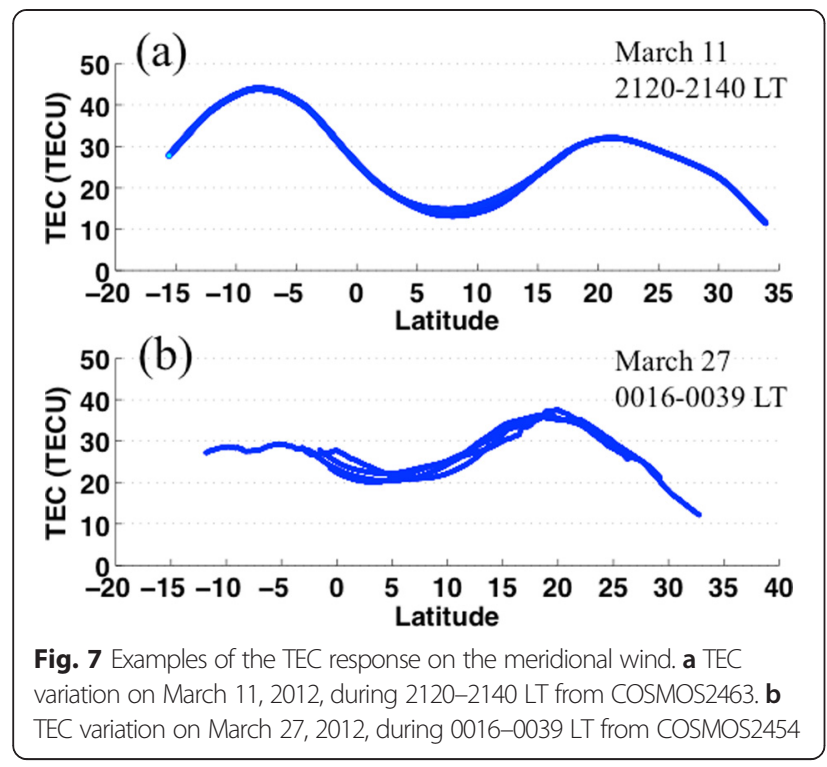

lower altitude thus decreases in content due to the high recombination rate.

Figure 8 shows the estimated meridional winds corresponding to the latitudinal TEC distributions of Fig. 6 . Figure $6 \mathrm{a}$ shows the TEC response to the northward wind on March 11, 2012, during 2120-2140 LT from COSMOS2463. The TEC was 32.1 TECU in the northern hemisphere and was 44.0 TECU in the southern hemisphere. The TEC in the northern hemisphere was 11.9 TECU lower than the TEC in the southern hemisphere when the northward wind appeared. The northward wind speed was $36 \mathrm{~m} / \mathrm{s}$. The ratio of the crest-tocrest TEC deviation to the meridional wind speed was about $0.3 \mathrm{TECU}$ per $1 \mathrm{~m} / \mathrm{s}$. The meridional wind had a northward direction from 1950 LT. This means that the delay between the TEC and the meridional wind was probably within one and a half hours. Figure $6 \mathrm{~b}$ shows the TEC response to the southward wind on March 27, 2012, during 0016-0039 LT from COSMOS2454. The TEC was 29.3 TECU in the southern hemisphere and was 37.5 TECU in the northern hemisphere. The TEC in the southern hemisphere was 8.2 TECU lower than the TEC in the northern hemisphere when the southward wind appeared. The southward wind speed was $27.5 \mathrm{~m} / \mathrm{s}$. The ratio of the crest-to-crest TEC deviation to the meridional wind speed was 0.3 TECU per $1 \mathrm{~m} / \mathrm{s}$. The meridional wind had a southward direction from 2300 LT on March 26,2012 . The time delay would probably be within one and quarter hours.

Estimation of meridional wind, however, is successful for only limited cases. The availability of ionosonde data, which can be used to estimate meridional wind, is limited by the ionosonde operating condition and the absence of an intense ESF. Because an intense ESF appears

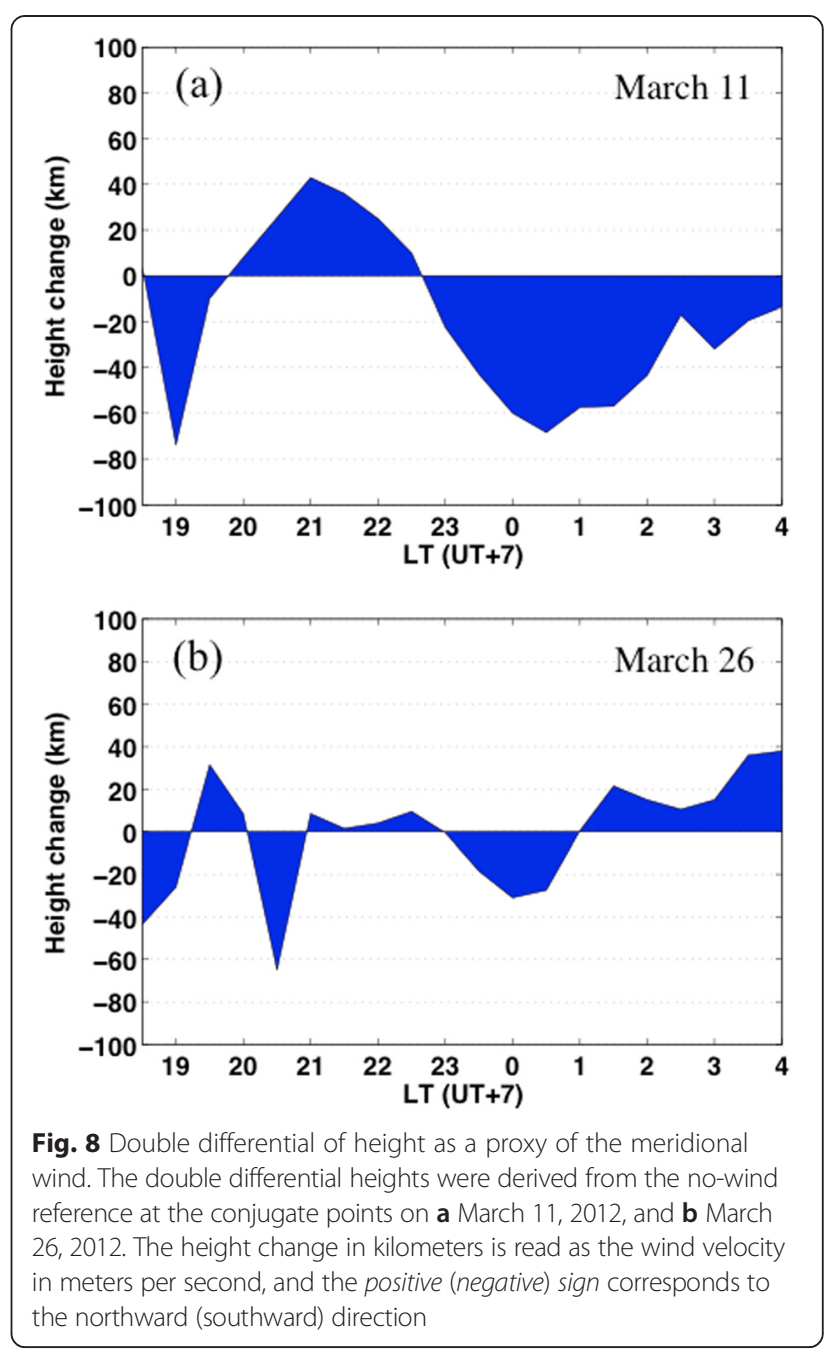

as a spread trace in an ionogram, it is difficult to scale the ionogram precisely. To investigate the nighttime TEC response to the meridional wind in Southeast Asia, simultaneous availability of TEC data and ionosonde data is necessary. The number of satellite passes and the quality of the beacon signal, which is determined by its signal-to-noise-ratio (SNR) level, limit TEC availability. With these limitations, nine cases in March 2012 were found to be suitable for the investigation. The nine cases included four cases for the TEC response to the northward wind, three cases for the TEC response to the southward wind, one case during the quiet wind on the ESF active day, and one case for no response. By discarding the quiet wind case, seven of the remaining eight cases behaved as expected. The response delay was found to be within one and one quarter hours. The average ratio of the crest-to-crest TEC deviation to the meridional wind speed was 0.3 TECU per $1 \mathrm{~m} / \mathrm{s}$.

Daytime asymmetry is shown in Fig. 4. The locations of the crests varied drastically by time. Strong EIA strength indicates that intense electric fields were seen 
in the daytime of March 7-9, when geomagnetic activity was high. This is the result of the production of an enhanced penetrating electric field during the geomagnetic storm. Daytime EIA is quite symmetric on March 7, whereas it is asymmetric on March 8-9. The asymmetry on March 8-9 could be generated by the neutral wind. The changes in EIA asymmetry on March 8-9, 2012, from the 11-13 LT bin to the 14-16 LT bin indicate rapid evolution of the TEC asymmetry, suggesting a rapid change of the neutral wind during the times.

Considering Fig. 5, there is no strong north-south asymmetry in the 17-19 LT bin on March 6, 8, and 9, 2012. Drastic TEC changes from the 14-16 LT bin to the 17-19 LT bin are seen on both quiet (March 6, 2012) and disturbed days (March 8 and 9, 2012). The TEC values decrease about $50 \%$ from the 14-16 LT bin to the 17-19 LT bin. On March 9, 2012, it is clear that the shapes of the north-south asymmetry and the TEC values in the 14-16 LT bin and in the 17-19 LT bin are drastically different. The severe asymmetry in the 14-16 LT bin becomes fairly asymmetric in the 17-19 LT bin with a reversed dominant crest. Note that the indicated geomagnetic activity on March 9, 2012, is severe storm. Such a rapid evolution of the north-south asymmetry on March 9, 2012, makes temporal prediction of the TEC around the EIA crests difficult.

As mentioned above, meridional wind is the main source of the EIA asymmetry. Neutral wind variation can be generated by forcing from the lower atmosphere, i.e., tides and waves, or forcing from the magnetosphere, i.e., the wind induced by the geomagnetic storm. However, we could not identify the source of the wind behavior in this research. Local operation of the GRBR network improves the dataset of temporal change of EIA asymmetry, especially when we compare it to in situ observation for which data are available at only certain altitudes.

\section{Conclusions}

The meridional GRBR network in Thailand-Indonesia was used to clarify the precise asymmetric structure of EIA. EIA asymmetry was successfully captured at the March equinox, when symmetric EIA was expected. From 1 month of data, 97 passes in March 2012, we successfully showed the day-to-day variability of EIA. Daily variation of the TEC values and the locations of the EIA crests along longitude $\sim 100^{\circ} \mathrm{E}$ was precisely observed. North/south asymmetries were found at both daytime and nighttime. In daytime, the EIA strength variability was found to be proportional to the enhanced penetrating electric field associated with magnetospheric activity. Rapid evolution of EIA asymmetry during daytime was seen on geomagnetic disturbed days, although the penetrating electric field could not have formed the asymmetry. Instead, when neutral wind forces on the intense EIA exist during the penetrating electric field enhancement, it produces severe asymmetry of the EIA with respect to the high background TEC. Such rapid evolution of EIA asymmetry was not seen during nighttime. Meridional wind mainly controlled the asymmetric structures at nighttime. We found direct variation between the speed of the thermospheric northward (southward) wind and reduction of the TEC value in the northern (southern) hemisphere, which is evidence of an influence from the bottom-side ionosphere. Local operation of the GRBR network improves the dataset of precise temporal change of EIA asymmetry, which leads to an improvement of capability for ionospheric prediction (Watthanasangmechai et al. 2010, 2012) in Southeast Asia. We plan to expand the dataset to deepen knowledge of EIA behavior in future work.

\section{Competing interests}

The authors declare that they have no competing interests.

\section{Authors' contributions}

KW and MY installed the GRBR receivers. KW processed all data used in the paper and led the investigation with contributions from MY, AS, TM, and TY. $\mathrm{MN}$ and $\mathrm{MI}$ supported the scaled ionosonde data. KW prepared the manuscript with contributions from all co-authors. All authors read and approved the final manuscript.

\section{Acknowledgments}

This work was supported by JSPS KAKENHI Grant Numbers 22403011, 25302007, and 15H02135 and MEXT Strategic Funds for the Promotion of Science and Technology. We thank Dr. Pornchai Supnithi and Dr. Clara Yono Yatini for local operation of GRBRs, Dr. Koichi Chen for valuable comments, and Dr. Takuya Tsugawa for his continued support and discussion.

\section{Author details}

${ }^{1}$ Research Institute for Sustainable Humanosphere (RISH), Kyoto University, Kyoto, Japan. ${ }^{2}$ Department of Geophysics, Kyoto University, Kyoto, Japan. ${ }^{3}$ National Institute of Information and Communications Technology, Tokyo, Japan.

Received: 13 November 2014 Accepted: 18 May 2015 Published online: 27 May 2015

\section{References}

Aydogdu M (1988) North-south asymmetry in the ionospheric equatorial anomaly in the African and West Asian regions produced by asymmetrical thermospheric winds. J Atmos Solar-Terr Phys 50:623-627. doi:10.1016/00219169(88)90060-8

Bailey DK (1948) The geomagnetic nature of the F2 layer longitude effect. Terr Magn Atmos Elect 53:35-39

Chen PR (1992) Two day oscillation of the equatorial ionization anomaly. J Geophys Res 97:6343-6357

Chen CH, Liu JY, Yumoto K, Lin CH, Fang TW (2008) Equatorial ionization anomaly of the total electron content and equatorial electrojet of groundbased geomagnetic field strength. J Atmos Solar-Terr Phys 70(17):2172-2183

Cheng CZ, Kuo YH, Anthes RA, Wu L (2006) Satellite constellation monitors global and space weather. Eos Trans AGU 87(17):166

Cherniak I, Zakharenkova I, Krankowski A (2014) Approaches for modeling ionosphere irregularities based on the TEC rate index. Earth Planets Space 66:165. doi:10.1186/s40623-014-0165-z

Colerico MJ, Mendillo M, Fesen CG, Meriwether J (2006) Comparative investigations of equatorial electrodynamics and low-to-mid latitude coupling of the thermosphere-ionosphere system. Ann Geophys 24:503-513 
Forbes JM, Guffe R, Zang X, Fritts D, Riggin D, Manson A, Meek C, Vincent R (1997) Quasi-2-day oscillation of the ionosphere during summer 1992. J Geophys Res 102:7301-7305

Gulyaeva TL, Arikan F, Stanislawska I (2011) Inter-hemispheric imaging of the ionosphere with the upgraded IRI-Plas model during the space weather storms. Earth Planets Space 63:929-939. doi:10.5047/eps.2011.04.007

Kelley MC (2009) The Earth's ionosphere, second edition: plasma physics \& electrodynamics. International geophysics series. Academic, San Diego, California, p 96, ISBN: 978-0-12-088425-4

Kenpankho P, Supnithi P, Tsugawa T, Maruyama T (2011) Variation of ionospheric slab thickness observations at Chumphon equatorial magnetic location. Earth Planets Space 63:359-364. doi:10.5047/eps.2011.03.003

Klimenko MV, Klimenko W, Ratovsky KG, Goncharenko LP (2012) Numerical modeling of the global ionospheric effects of storm sequence on September 9-14, 2005-comparison with IRI model. Earth Planets Space 64(6):433-440. doi:10.5047/eps.2011.06.048

Kumar S, Tan EL, Razul SG, See CMS, Siingh D (2014) Validation of the IRI-2012 model with GPS-based ground observation over a low-latitude Singapore station. Earth Planets Space 66:17. doi:10.1186/1880-5981-66-17

Kutiev I, Otsuka Y, Saito A, Watanabe S (2006) GPS observations of post-storm TEC enhancements at low latitudes. Earth Planets Space 58:1479-1486. doi:10.1186/BF03352647

Lin C, Liu J, Tsai H, Cheng C (2007a) Variations in the equatorial ionization anomaly peaks in the western Pacific region during the geomagnetic storms of April 6 and July 15, 2000. Earth Planets Space 59:401-405. doi:10.1186/ BF03352701

Lin CH, Liu JY, Fang TW, Chang PY, Tsai HF, Chen CH, Hsiao CC (2007b) Motions of the equatorial ionization anomaly crests imaged by FORMOSAT-3/COSMIC Geophys Res Lett 34:L19101. doi:10.1029/2007GL030741

Liu L, Wan W, Lee CC, Ning B, Liu JY (2004) The low latitude ionospheric effects of the April 2000 magnetic storm near the longitude $120^{\circ} \mathrm{E}$. Earth Planets Space 56:607-612. doi:10.1186/BF03352521

Martyn DF (1955) Theory of height and ionization density changes at the maximum of a Chapman-like region, taking account of ion production, decay, diffusion and total drift. In: Proceedings Cambridge Conference. Physical Society, London, p 254

Maruyama T (1996) Modeling study of equatorial ionospheric height and spread F occurrence. J Geophys Res 101:5157-5163

Maruyama T, Saito S, Kawamura M, Nozaki K (2008) Thermospheric meridional winds as deduced from ionosonde chain and equatorial latitudes and their connection with mid-night temperature maximum. J Geophys Res 113:A09316. doi:10.1029/2008JA013031

Maruyama T, Saito S, Kawamura M, Nozaki K, Krall J, Huba JD (2009) Equinoctial asymmetry of a low-latitude ionosphere-thermosphere system and equatorial irregularities: evidence for meridional wind control. Ann Geophys 27:2027-2034

Mitra SK (1946) Geomagnetic control of region $F_{2}$ of the ionosphere. Nature 158:668

Namba S, Maeda KI (1939) Radio wave propagation (in Japanese). Corona Publishing, Tokyo, p 86

Nishida A (2009) Early Japanese contributions to space weather research — 1945-1960, Climate and Weather of the Sun-Earth System (CAWSES): selected papers from the 2007 Kyoto Symposium. Edited by Tsuda T, Fujii R, Shibata K, and Geller MA, Terrapub: 1-22

Pancheva D, Lysenko I (1988) Quasi-2-day fluctuations observed in the summer F-region electron maximum. Bulgarian Geophys J 14:41-51

Pancheva D, Mithell NJ, Manson AH (2004) Variability of the quasi-2-day wave observed in the MLT region during the PSMOS campaign of June-August 1999. J Atmos Solar-Terr Phys 66:539-565

Pancheva DV, Mukhtarov PJ, Shepherd MG, Mitchell NJ, Fritts DC, Riggin DM, Franke SJ, Batista PP, Abdu MA, Batista IS, Clemesha BR, Kikuchi T (2006) Two-day wave coupling of the low-latitude atmosphere-ionosphere system. J Geophys Res 111:A07313. doi:10.1029/2005JA011562

Reigber C, Luhr H, Schwintzer P (2002) CHAMP mission status. Adv Space Res 30:129-134

Rishbeth H (2000) The equatorial F-layer: progress and puzzles. Ann Geophys 18:730-739

Schunk RW, Nagy AF (2009) lonospheres physics, plasma physics, and chemistry, 2nd edn, Atmospheric and space science series. Cambridge University Press, New York, ISBN: 978-0-521-87706-0
Simi KG, Manju G, Madhav Haridas K, Prabhakaran Nayar SR, Pant TK, Alex S (2013) lonospheric response to a geomagnetic storm during November 8-10, 2004. Earth Planets Space 65:343-350. doi:10.5047/eps.2012.09.005

Stolle C, Manoj C, Luhr H, Maus S, Alken P (2008) Estimating the daytime equatorial ionization anomaly strength from electric field proxies. J Geophys Res 113:A09310. doi:10.1029/2007JA012781

Takahashi H, Lima LM, Wrasse CM, Batista IS, Onohara A, Aquino MGS, Batista PP Abdu MA (2012) lonospheric response to 2-day planetary wave in the equatorial and low latitude regions. J Atmos Terr Phys 90-91:164-171

Tapley BD, Bettadpur S, Watkins M, Reigber C (2004) The gravity recovery and climate experiment: mission overview and early results. Geophys Res Lett 31:L09607. doi:10.1029/2004GL019920

Uemoto J, Ono T, Maruyama T, Saito S, Lizima M, Kumamoto A (2007) Magnetic conjugate observation of the F-3 layer using the SEALION ionosonde network. Geophys Res Lett 34(2). doi: 10.1029/2006GL028783

Watthanasangmechai K, Supnithi P, Lerkvaranyu S, Maruyama T (2010) Hourly and seasonal TEC prediction with neural network at Chumphon equatorial latitude station, Thailand. In: Proceeding of the 25th international technical conference on circuits/systems, computer and communications, Pattaya, Thailand, 796-799

Watthanasangmechai K, Supnithi P, Lerkvaranyu S, Tsugawa T, Nagatsuma T, Maruyama T (2012) TEC prediction with neural network for equatorial latitude station in Thailand. Earth Planets Space 64:473-483. doi:10.5047/ eps.2011.05.025

Watthanasangmechai K, Yamamoto M, Saito A, Tsugawa T, Yokoyama T, Supnithi P, Yatini C (2014) Latitudinal GRBR-TEC estimation in Southeast Asia region based on the two-station method. Radio Sci 49:910-920. doi:10.1002/ 2013 RSO05347

Xiong C, Luhr H, Ma SY (2013) The magnitude and inter-hemispheric asymmetry of equatorial ionization anomaly-based on CHAMP and GRACE observations. J Atmos Solar-Terr Phys 105-106:160-169

Yamamoto M (2008) Digital beacon receiver for ionospheric TEC measurement developed with GNU Radio. Earth Planets Space 60:e21-e24. doi:10.1186/ BF03353137

Yeh HC, Franke SJ, Yeh KC, Liu CH, Raymund TD, Chen HH, Izotove AV, Liu JY, Wu J, Lin KH, Chen SW (1994) Low-latitude ionospheric tomography network along Taiwan meridian. In: Kuo FS (ed) Low-latitude ionospheric physics, COSPAR Colloquia Series. Elsevier Science, New York, pp 295-303, 7

Yeh KC, Franke SJ, Andreeva ES, Kunitsyn VE (2001) An investigation of motions of the equatorial anomaly crest. Geophys Res Lett 28(24):4517-4520

\section{Submit your manuscript to a SpringerOpen ${ }^{\circ}$ journal and benefit from:}

- Convenient online submission

- Rigorous peer review

- Immediate publication on acceptance

- Open access: articles freely available online

- High visibility within the field

- Retaining the copyright to your article

Submit your next manuscript at springeropen.com 